BDX-613-1381 (Rev.)

Distribution Category UC-38

DIGITAL RECORDING AND

ANALYSIS OF FAST EBW

BURST WAVEFORMS

Published August 1976

Project Leader:

J. R. Lembke

Department 812

Project Team :

A. L. Tindall

PDO 6984883

Topical Report

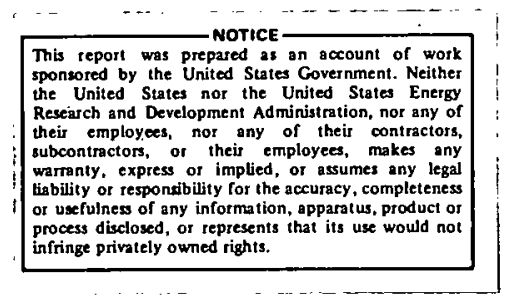

Technical Communications

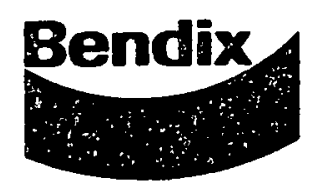

Kansas City

Division

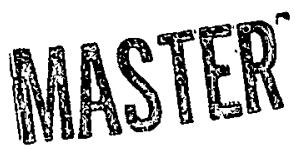

OTE $E(29-1)-6 / 3$

DTSTRIBUTION QF TUIS HOSUREMY IS UNLIMITED 


\section{DISCLAIMER}

This report was prepared as an account of work sponsored by an agency of the United States Government. Neither the United States Government nor any agency Thereof, nor any of their employees, makes any warranty, express or implied, or assumes any legal liability or responsibility for the accuracy, completeness, or usefulness of any information, apparatus, product, or process disclosed, or represents that its use would not infringe privately owned rights. Reference herein to any specific commercial product, process, or service by trade name, trademark, manufacturer, or otherwise does not necessarily constitute or imply its endorsement, recommendation, or favoring by the United States Government or any agency thereof. The views and opinions of authors expressed herein do not necessarily state or reflect those of the United States Government or any agency thereof. 


\section{DISCLAIMER}

Portions of this document may be illegible in electronic image products. Images are produced from the best available original document. 


\title{
DIGITAL RECORDING AND ANALYSIS OF FAST EBW BURST WAVEFORMS
}

\author{
BDX-613-1381 (Rev.), UNCLASSIFIED Topical Report, Published \\ August 1976
}

Prepared by J. R. Lembke, D/812, under PDO 6984883

A commercial transient digitizer with 10-nanosecond resolution was applied to the measurement of exploding bridgewire dynamic test waveforms. A vidicon digitizer was built to extend the resolution for this type of measurement to less than 1 ns. Both digitizers were interfaced to a minicomputer to permit automatic evaluation of waveform characteristics and computation of functions of two simultaneous waveforms.

WPC-sp

This report was prepared as an account of work sponsored by the United States Government. Neither the United States nor the United States Energy Research and Development Administration, nor any of their employees, nor any of their contractors, subcontractors, or their employees, makes any warranty, express or implied, or assumes any legal liability or responsibility for the accuracy, completeness or usefulness of any information, apparatus, product or process disclosed, or represents that its use would not infringe privately owned rights.
THE BENDIX CORPORATION

KANSAS CITY DIVISION

P.O. BOX 1159

KANSAS CITY, MISSOURI 64141

A prime contractor for the United States Energy Research and Development Administration

Contract Number E(29-1)-613 USERDA 


\section{CONTENTS}

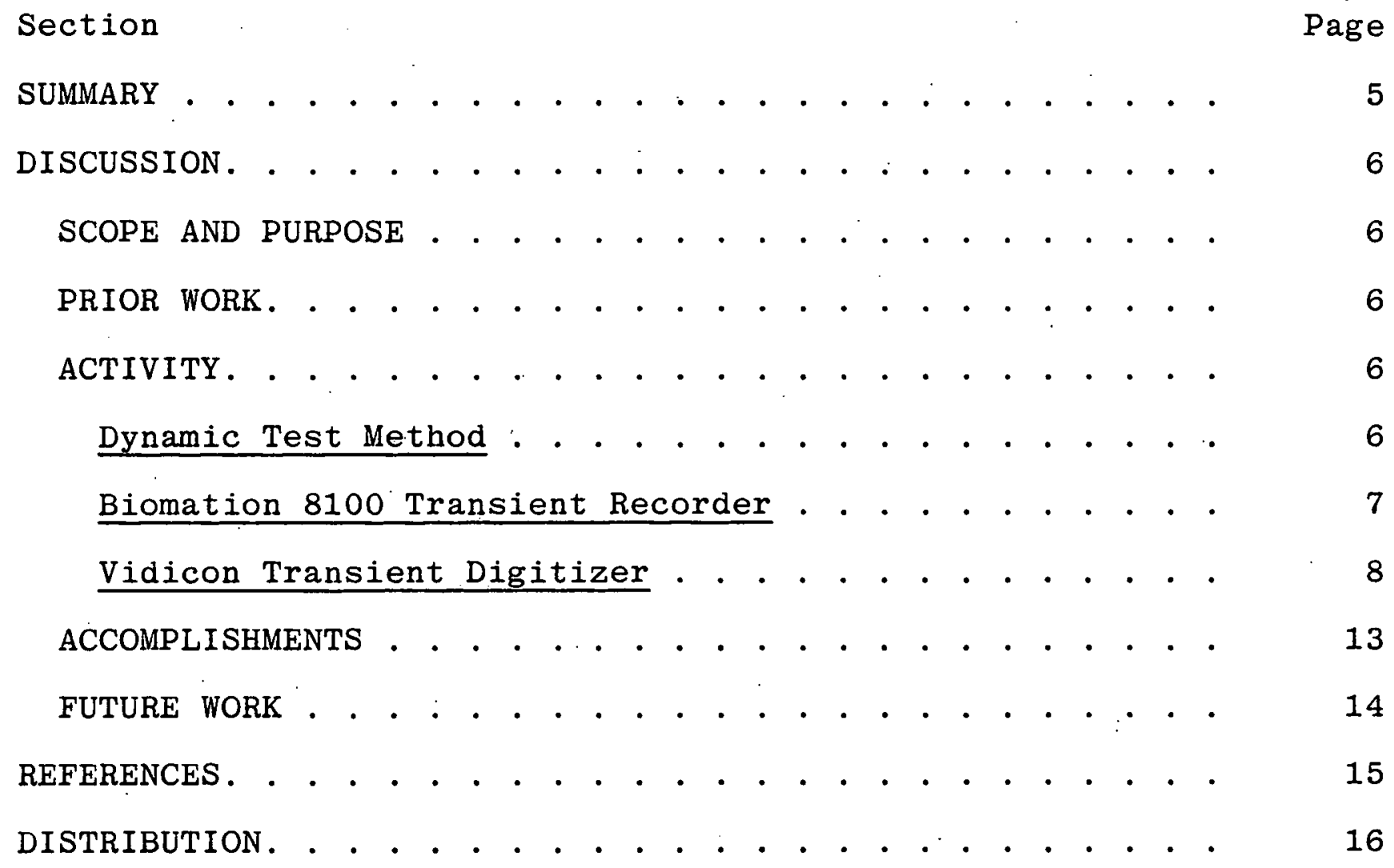




\section{ILLUSTRATIONS}

Figure

Page

1

Dynamic Test System . . . . . . . . . . .

Digitized dv/dt Waveform From Data Collected by Biomation 8100 . . . . . . . . . . . . . . .

Voltage Waveform Synthesized by Numerical Integration of the Data in Figure $2 . . . . .$.

Vidicon Transient Digitizer (Polaroid). . . . .

Test Pulse Displayed on Oscilloscope of Vidicon Digitizer (P-90584) . . . . . . . . . . . .

Digitized Replica of Pulse in Figure 5 Reconstructed on Display Monitor of Vidicon Digitizer (P-90570) . . . . . . . . . . . 
As part of an overall project to develop improved methods of characterizing the quality of exploding bridgewires (EBW), the problems associated with digital recording of fast transient EBW waveforms were analyzed and two recording systems were implemented. Analysis of the recorded data by digital computer was also initiated.

A Biomation Model 8100 Transient Recorder.was evaluated first and performed successfully. However, the 8100 was limited to $10 \mathrm{~ns}$ resolution. A vidicon transient digitizer developed at Sandia Laboratories, Albuquerque, and having a sampling interval significantly less than $1 \mathrm{~ns}$, was evaluated next and appears to be more suitable for the EBW characterization problem. Computer hardware and software for the storage and manipulation of the data obtained from both types of equipment has been designed.

Much of the future work on this project will be concerned with developing new software. In addition, a data base will be developed consisting of waveforms from bridgewires of known quality and from wires with controlled defects. 


\section{DISCUSSION}

\section{SCOPE AND PURPOSE}

The goal of this project was to develop improved methods of characterizing the quality of bridgewires by making more complete use of the information available in various waveforms which occur during exploding bridgewire (EBW) burst.

\section{PRIOR WORK}

Development of the dynamic EBW test system and work on related techniques have been reported previously. No prior work on digitizing EBW transient waveforms has been reported at Bendix.

\section{ACTIVITY}

Dynamic Test Method

Dynamic testing. is accomplished by exploding an. EBW element, using a capacitive discharge firing unit (CDU). The equivalent firing circuit is shown in Figure 1 .

Several waveforms can be monitored during the firing process. Figure 1 shows how $\mathrm{di} / \mathrm{dt}$ and $\mathrm{dv} / \mathrm{dt}$ can be monitored. In the past, these waveforms have been used to trigger a time interval meter to measure burst time, and the general waveform configuration has been observed or photographed on an oscilloscope. This has provided useful information, but more detailed analysis of voltage and current waveforms during burst is essential for adequate characterization of EBW performance in new applications.

Typical waveform durations are on the order of a few hundred nanoseconds. Numerical analysis of the waveforms requires that the amplitude be digitized at intervals of 10 ns or less. Rapidly changing waveforms require digitizing intervals of 1 ns or less.

Once the digital waveform description is obtained, a computer can be used to perform analyses and d.rive functions of several waveforms. If two adequate recording channels are available, voltage and current waveforms can be recorded simultaneously, and the power and energy waveforms can be computed. 


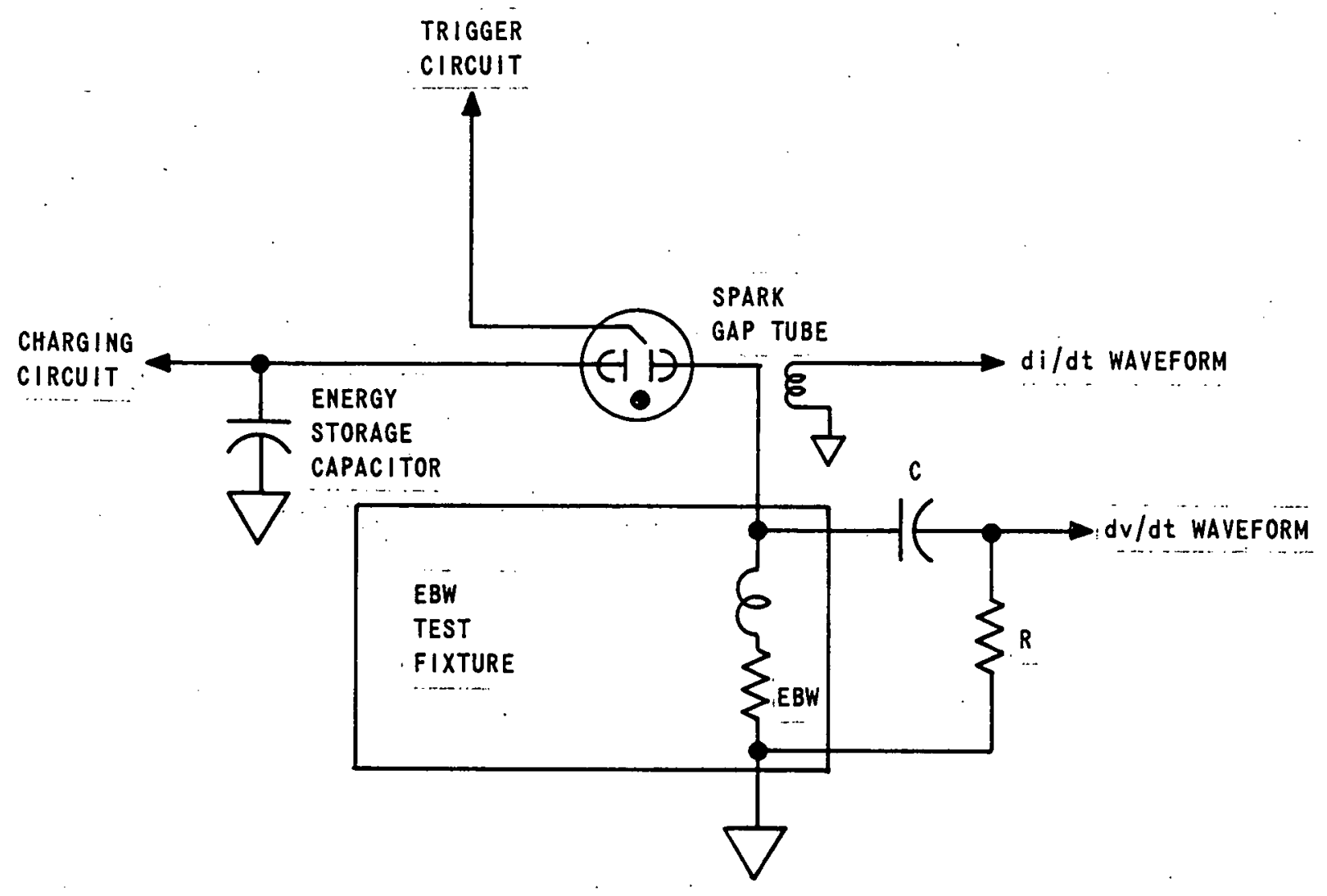

Figure 1. Dynamic Test System

Biomation 8100 Transient Recorder

The Biomation Model 8100 Transient Recorder is a solid state instrument which converts transient waveforms to digital form and stores the record for transmission to a computer. Each digitized sample is stored as an eight-bit word, and storage capacity is 2024 words. Input sensitivity and sample rate can be varied over a wide range, but in this application the fastest available sample rate, $10 \mathrm{~ns}$ per sample, is normally needed. At this sample rate the total record time is over $20 \mu \mathrm{s}$, much more than is normally required. Input bandwidth is $25 \mathrm{MHz}$.

All recording functions of the instrument are remotely programmable. Since the front panel controls are relatively complex, development of a programmed operating sequence would minimize the opportunity for operator error and assure consistent recorder setup.

The Model 8100 was interfaced to a PDP 11/05 minicomputer. Driver programs were written to permit setup of the 8100 and to transfer the recorded data to the computer. The system was used to capture various EBW burst waveforms, and additional programs were developed to compute burst time and to perform numerical integration. 
Figure 2 illustrates a typical recorded waveform, the time derivative of EBW voltage (dv/dt). "Each "+" symbol represents a digitized voltage sample, and these occur at 10-ns intervals. The data points are connected by straight line segments (as approximated by an electrostatic plotter).

The digitized waveforms are generally in good agreement with oscilloscope photographs, with two primary exceptions. First, since the time resolution is $10 \mathrm{~ns}$, sharp peaks are frequently straddled by the digitizing process, causing the peak amplitude to be lost. Second, the eight-bit digital word size limits the amplitude resolution attainable and results in a somewhat "stepped" appearance of the plotted data.

Current initiation is indicated by an abrupt rise in $\mathrm{dv} / \mathrm{dt}$, caused by the inductive components in the EBW element and in the burst fixture. At burst, the trace again rises and then falls sharply negative. Burst: time is taken as the time interval from current initiation until the zero crossing following the second $\mathrm{dv} / \mathrm{dt}$ peak. This time can be computed by analysis of the digitized waveform data and typically is in agreement with direct measurements of burst time within less than $10 \mathrm{~ns}$.

The waveform of EBW burst voltage can be synthesized from the digitized $\mathrm{dv} / \mathrm{dt}$ waveform by numerical integration. Figure 3 represents the results of this process applied to the data in Figure 2 and is an indication of the types of digital waveform analysis which are available.

The data presented in Figures. 2 and 3 represent processes which were performed completely under computer control. EBW burst was performed manually, but the"digitizer operation, data transfer, data analysis, scaling, and plotting were all controlled by specialized computer software.

Vidicon Transient Digitizer

The Biomation 8100 has performed successfully, but it is limited to 10-ns resolution. Improved resolution is needed to capture the faster EBW waveforms. A vidicon transient digitizer developed at Sandia Laboratories, Albuquerque (SLA) has achieved sampling intervals significantly "less than 1 ns and appears to be well suited to the EBW characterization problem. ${ }^{1}$ A device of this type was built by Bendix (BKC) for application to EBW measurement.

The vidicon transient digitizer contains a modified television camera with vertical sweep and a silicon-diode-array vidicon. The camera is used to view a transient waveform as displayed on a conventional oscilloscope, and the transient image is retained by the silicon diode array long enough to be scanned out by the vidicon electron gun. A threshold circuit detects points at 


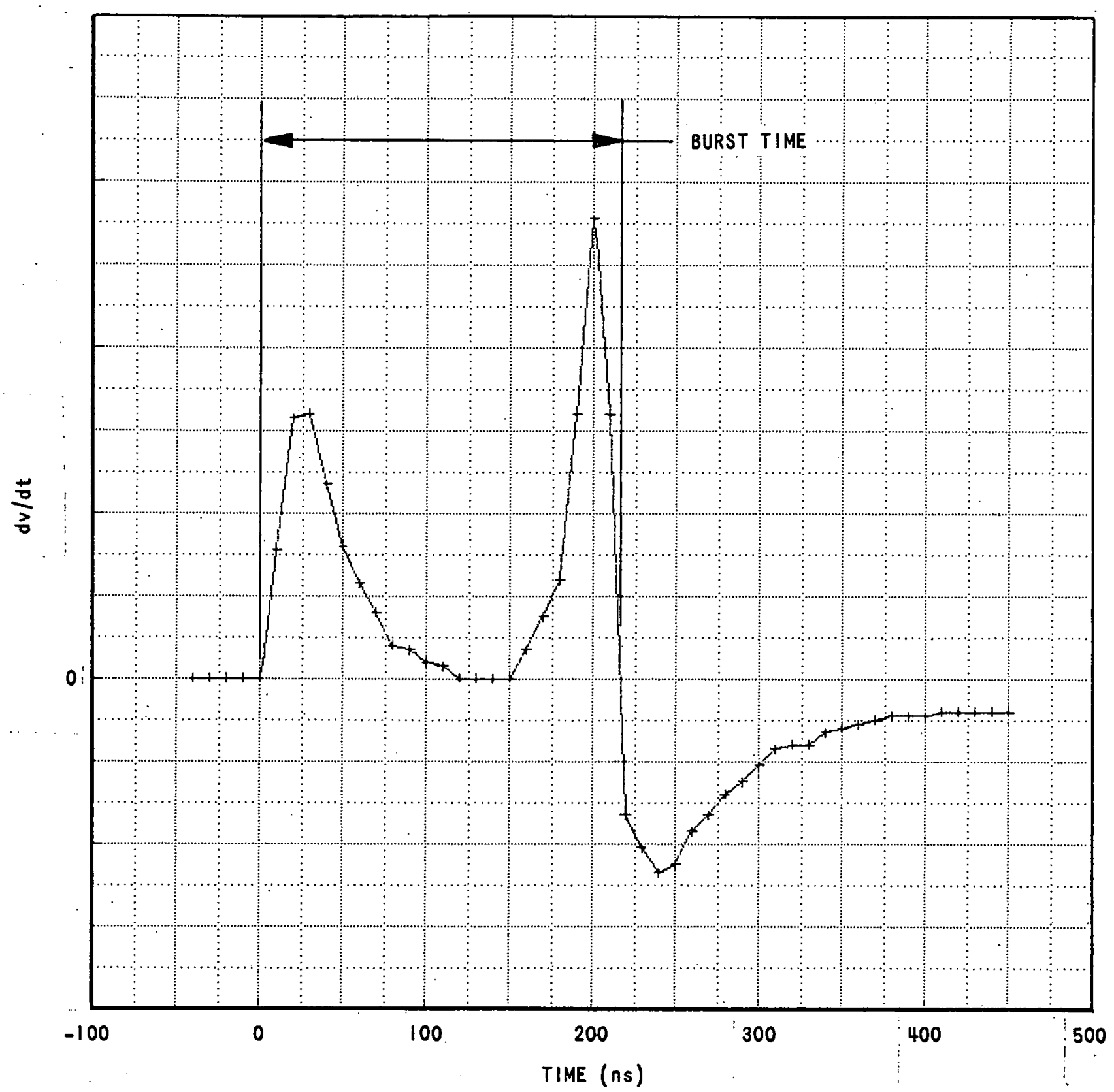

Figure 2. Digitized dv/dt Waveform From Data Collected by Biomation 8100

which the vidicon sweep crosses the oscilloscope trace, and counting circuits are used to digitize the times of the trace crossings, which are equivalent to amplitude samples. Five hundred samples are taken for each waveform, and these are stored for transmittal to a computer. A display of the stored digital waveform is provided on a monitor. Figure 4 illustrates the physical layout of the equipment. 


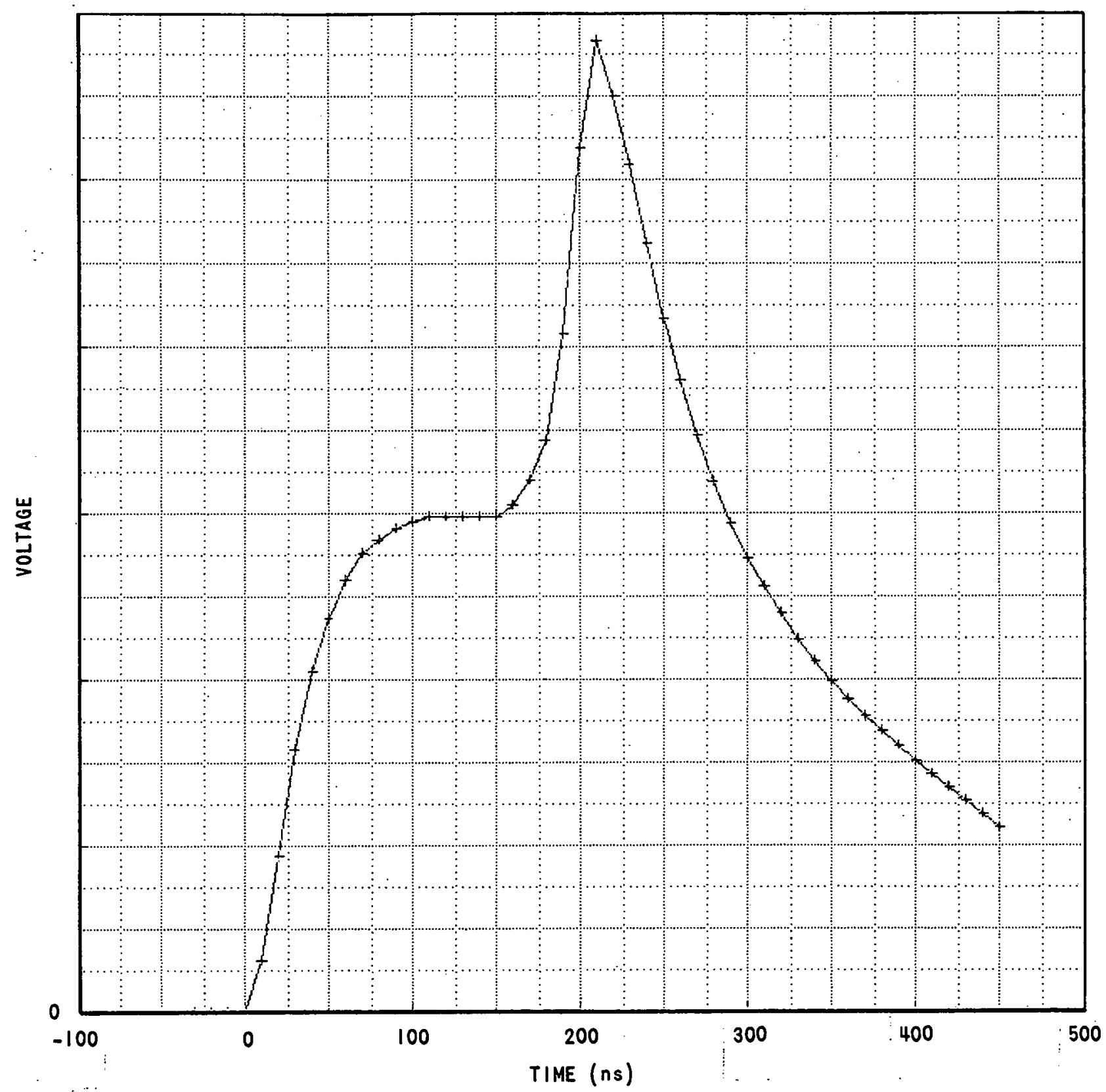

Figure 3. Voltage Waveform Synthesized by Numerical Integration of the Data in Figure. 2

An input test pulse and the digitized replica are shown in Figures 5 and 6 respectively. (These photographs were taken of a vidicon digitizer which was built by BKC for Los Alamos Scientific Laboratory. [LASL] WX-7. While functionally identical, the LASL digitizer has provision for direct observation of the oscilloscope.) The waveform shown in Figure 6 is constructed by scanning the 500 


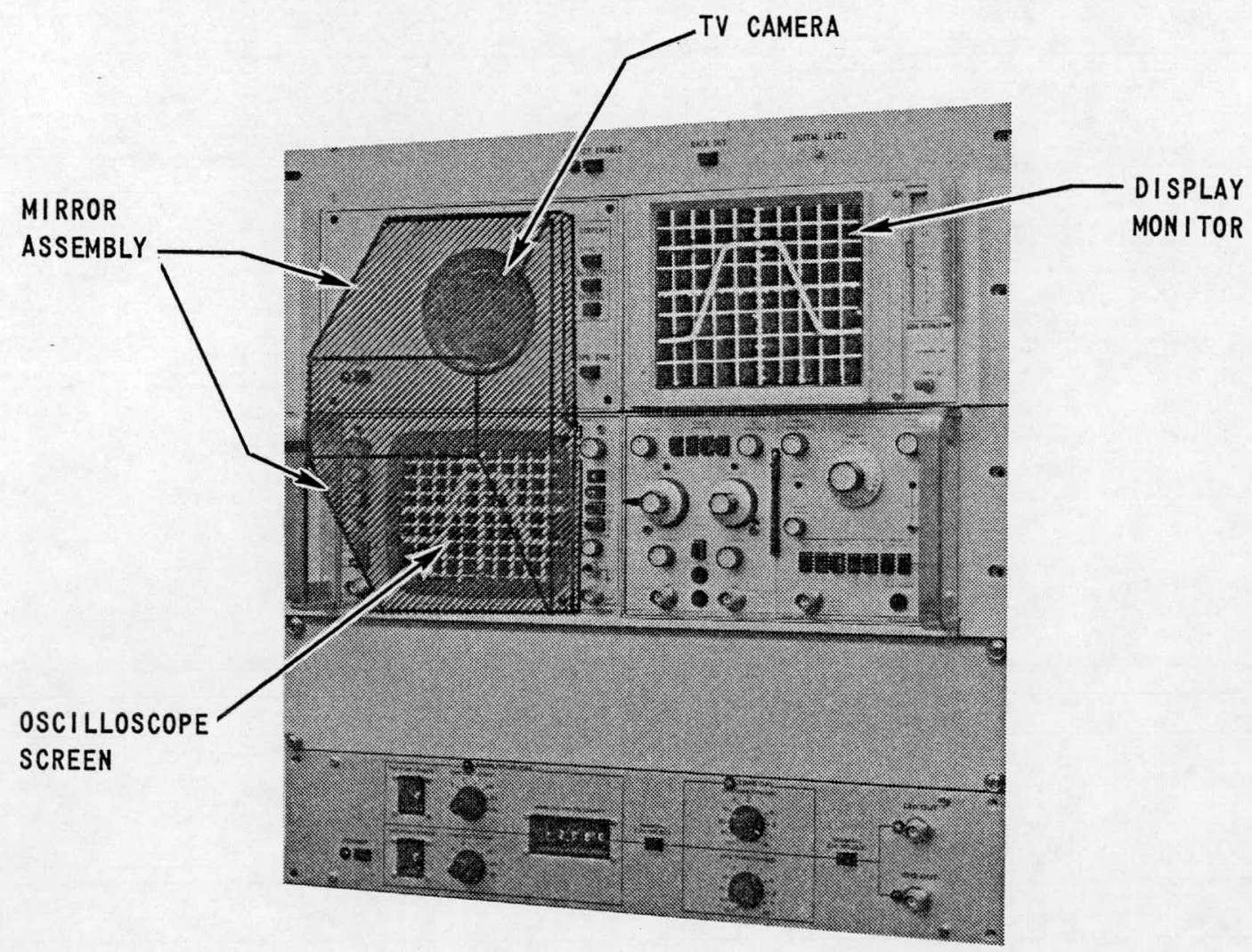

Figure 4. Vidicon Transient Digitizer

words in the digitizer memory, performing digital-to-analog conversion, and displaying the 500 analog values across the screen of a Tektronix 604 Monitor. All of these steps occur automatically.

The digitizer system includes a self-calibration capability, which is operated under computer control. Several precise dc voltage levels and a square wave generated by a crystal oscillator are displayed in sequence and digitized. The resulting digital values of voltage and time are retained by the computer and are used as calibration factors in analyzing actual test data.

Figure 7 is a dv/dt waveform, recorded at 1 -ns sample intervals by the vidicon digitizer. In regions where the waveform rises or falls rapidly, the oscilloscope trace becomes dim and the digitizer fails to detect the trace location. (This mechanism ultimately limits the sample rate which can be achieved.) SLA uses linear interpolation to fill in data points missed in this fashion. ${ }^{2}$ It is significant, however, that the peak values are normally captured, even when portions of the rise or fall are missed. This is an important advantage over the Biomation 8100 . 


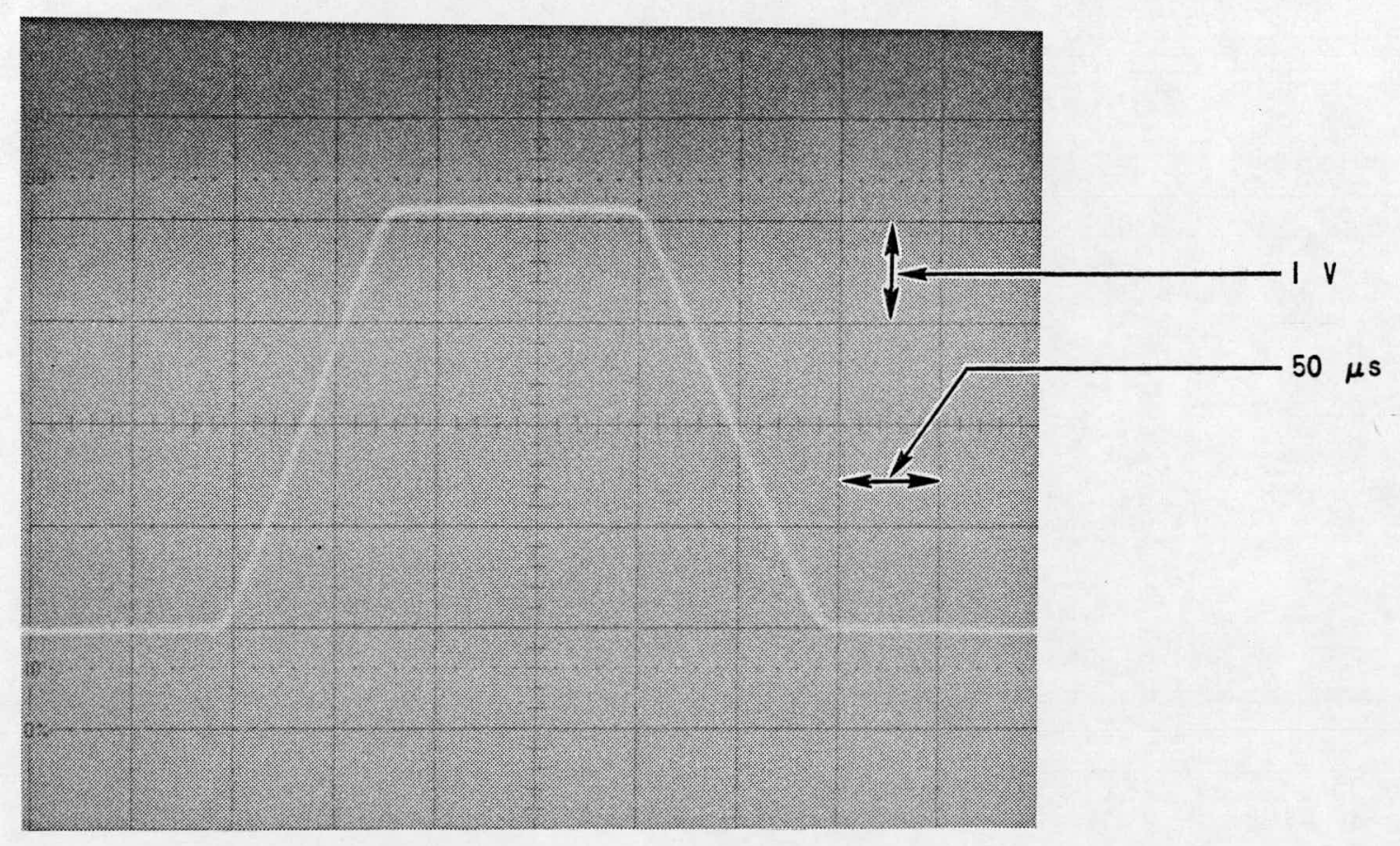

Figure 5. Test Pulse Displayed on Oscilloscope of Vidicon Digitizer

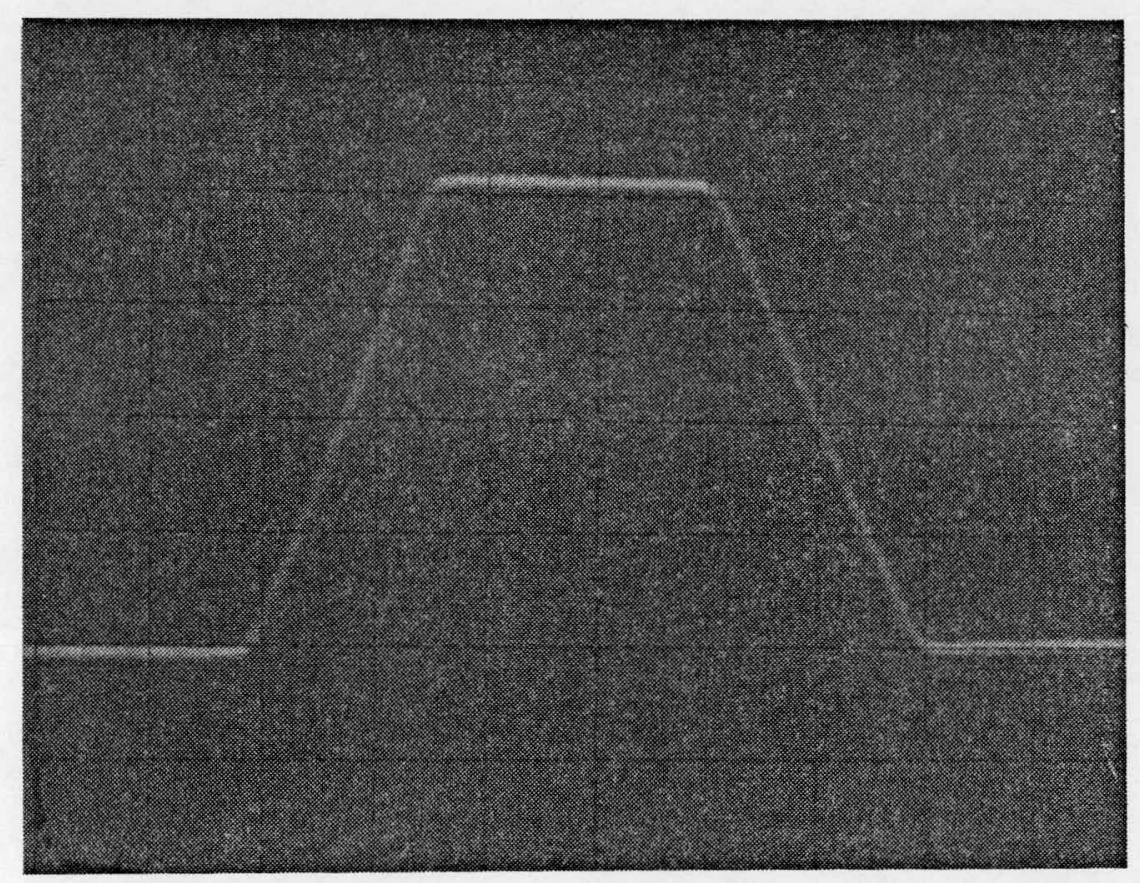

Figure 6. Digitized Replica of Pulse in Figure 5 Reconstructed on Display Monitor of Vidicon Digitizer 


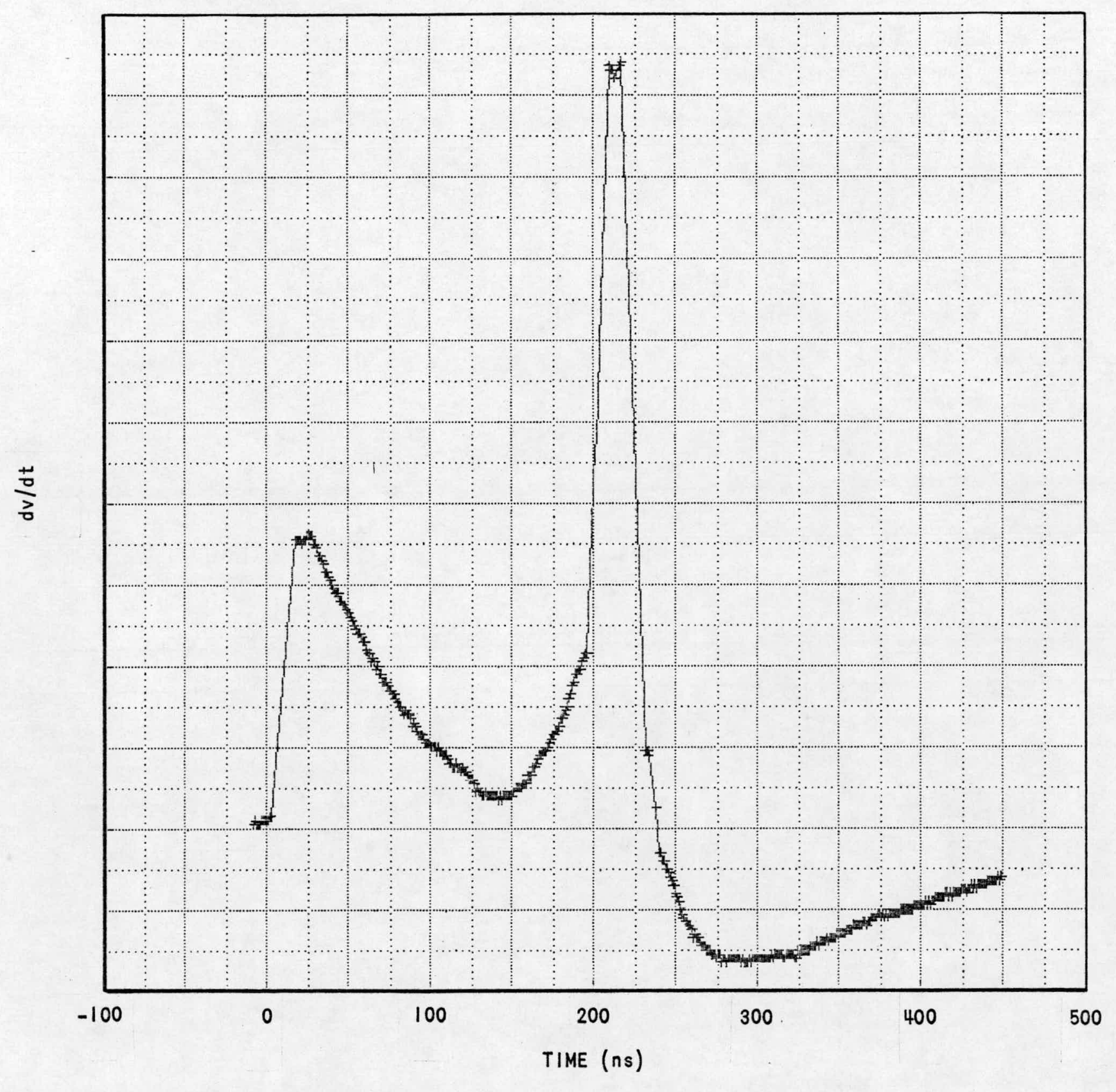

Figure 7. Waveform of $d v / d t$ as Recorded by Vidicon Transient Digitizer (Sample Interval is $1 \mathrm{~ns}$. )

\section{ACCOMPLISHMENTS}

A capability for recording EBW burst waveforms in digital form was established. Resolution of $10 \mathrm{~ns}$ was achieved with a commercial digitizer, and resolution of $1 \mathrm{~ns}$ was achieved with a vidicon digitizer fabricated for this project. Computer interfaces were 
designed and fabricated for both digitizers. Programs were written to facilitate computer processing of data from the digitizers, and a waveform plotting capability was established.

\section{FUTURE WORK}

Development of software to operate the vidicon digitizer is in progress. When completed, this will permit full checkout of the computer/digitizer interface and automatic calibration of digitized data. Ultimately, the goal is dual-channel digitizing of EBW data. The Biomation 8100 will be used for slower waveforms, such as burst current, while the vidicon digitizer will permit simultaneous capture of the faster waveforms.

Effort will be applied to minimization of timing ambiguity between the two independent channels. (Optimization will be limited by the 10-ns resolution of the Biomation 8100.) Programs will be written for dual-channel functional operations to synthesize such waveforms as energy and power.

Additional programs will be developed to optimize the performance of integration, differentiation, and interpolation, and to provide a selection of methods for these operations to suit individual data configurations. A cubic spline interpolation program (SPLINT) developed previously is expected to provide the basis for much of the needed software. ${ }^{3}$

Useful interpretation of digitized waveforms will require the generation of a data base consisting of waveforms from bridgewires of known quality and from wires with controlled defects. Some method of correlation with actual EBW performance must be devised.

Techniques will be developed for evaluating the EBW burst and for correcting the measured waveform data for the effects of stray measurement-circuit inductance, capacitance, and resistance.

Routine generation and analysis of EBW burst data will provide opportunity for improved understanding of the exploding wire process and of the effects of fabrication variables on detailed EBW behavior. Techniques for simulation of the burst process will benefit from empirical corrections to the assumed relationship between energy density and resistivity.

Ultimately, two digitizing channels with 1-ns resolution will probably be required. SLA has completed a prototype two-channel vidicon digitizer which will be evaluated for this application. 


\section{REFERENCES}

${ }^{1}$ G. R. Bachand, T. L. Evans and R. K. Treece, Vidicon Digitizing of oscizloscope Traces (Development Report). Sandia Laboratories, Albuquerque: SLA-73-0525, September, 1973.

${ }^{2}$ D. N. Harstad, Application Programs for the SE1045 Digitizer. Sandia Laboratories, Albuquerque: SLA-73-0367.

${ }^{3} \mathrm{~J}$. L. Walsh, J. H. Ahlberg, and E. N. Nilson, "Best Approximation Properties of the Spline Fit," Journal of Mathematics and Mechanics, Vol. 11, No. 2 (1962), pp 225-234. 
R. Bulcock, ERDA-KCAO

B. B. Fisher, LASL

R. McCormick, LASL

W. H. Meyers, LASL

G. A. Broadman, LLL

W. W. Hofer, LLL

J. R. Stroud, LLL

R. C. Weingart; LLL

J. R. Brinkman, Monsanto

D. A. Homan, Monsanto

G. R. Bachand, SLA

T. L. Evans, SLA

C. H. Beckham, SLL

J. S. Carson, D/142

J. D. Corey, D/554

L. Stratton, D/554

R. P. Frohmberg, D/800

J. C. Culver, D/812

J. R. Lembke, D/812

J. A. Peters, D/842

M. A. Ferrell, D/844

R. J. Powell, D/845

M. Gray, D/862

J. C. MCCOY, D/862

R. E. Kessler, D/864

W. E. Simes, D/864 